\title{
O ESTADO, A LIBERDADE E O DIREITO ADMINISTRATIVO
}

\author{
Eros Roberto Grau \\ Professor Titular do Departamento de Direito \\ Econômico-Financeiro da Faculdade de Direito da \\ Universidade de São Paulo
}

"Cum ignem accenderet, domum suam fumo implebat, non luce illustrabat"

ABELARDO'

Resumo:

$O$ individual sempre esteve entre nós inserido no Estado, de modo a conformar e a determinar o interesse público mesmo e especialmente o chamado interesse público primário. A noção que temos da coisa pública relaciona-a não ao povo, porém ao Estado. O público é o estatal, não o comum a todos. É o enfoque apontado pelo eminente professor.

Abstract:

The individual has always been inserted in the State, in such a way to form and determine even the public interest and specially the called primary public interest. Our notion of the public thing relates her not to the people, but to the State. The public isn't the public corporation, not the common for all. It's the focus pointed by the prominent professor.

Unitermos: Estado; liberdade; Direito Administrativo.

01. A análise do tema enunciado o Estado, a liberdade e o Direito Administrativo - exige a introdução de duas premissas, a primeira das quais repousa na impossibilidade de pensarmos o Direito "fechado" às demais ciências humanas ou culturais.

Lembrando a frase de Terêncio, recuperada pelo jovem Marx - "Sou homem: nada do que é humano me é estranho" nada do que é humano é estranho a quem se embrenhe no pensamento sobre o Direito, esse plano, essa instância, essa linguagem do social. ${ }^{2}$

1. Apud Pc. Orlando Vilela, O drama Heloisa-Abelarılo, scgunda cdição, Editora Itatiaia, Bclo Horizonte, 1986, p. 27. Para os que não sabem latim ou o esqueceram: "Se acendlia o fogo. enchict a casa de fiumaça, mas não a iluminava"

2. Vide meu O dirceito posto e o direito presstıposto, 4a cdição, Mallıciros Editorcs, São Paulo, p. 56. 
A visão do Direito como ciência "fechada" transforma o dogmático em um pobre tecnológo ou tecnocrata, nada mais do que um mero leguleio. ${ }^{3}$

Torna-se vítima de uma doença incurável quem não se dá conta de que como ensina Enrique Marít o discurso da ordem abrange o lugar da racionalidade [a lei] e o lugar do imaginário social como controle da disciplina das condutas humanas e da sua sujeição ao poder. Essa doença crônica que envelhece o jurista que pretende fazer ciência à custa do isolamento do direito, perdido em análises de conceitos, critérios descritivos e classificatórios das condutas que as normas proíbem ou autorizam, sacerdote de uma religião tão absurda como o mundo de Franz Kafka, ${ }^{5}$ isolado, ele próprio, da realidade, para, ingenuamente, "fazer o jogo" do poder.

02. Em segundo lugar, é necessário tomarmos consciência de que o individual sempre esteve, entre nós, inserido no Estado, de modo a conformar e a determinar o interesse público, mesmo e especialmente o chamado interesse público primário.

E assim é porque as virtudes republicanas são imanentes à ordem social, mas não podem realizar-se entre nós, porque essa ordem, aqui, é privatista."

A noção que temos da coisa pública relaciona-a não ao povo, porém ao Estado. O público é o estatal, não o comum a todos. Desconhecemos a sentença de Ulpiano $^{7}$ demarcando a distinção entre ambos: os bens pertencentes ao Estado são abusivamente chamados de "públicos", pois assim devem ser considerados unicamente os bens que pertencem ao povo romano. E desconhecemos também, inteiramente, a síntese de Cícero ${ }^{8}$ res publica, res populi.

O individualismo possessivo que toma conta de nós permite visualizarmos exclusivamente o que pertence a cada um e os bens que são ditos públicos assim são chamados porque arrebatados pelo Estado, este inimigo de cada um, concebido como instituição rigorosamente separada da sociedade.

Esse, o defeito essencial que vicia o pensamento de nossos juristas, carentes de vocação para a crítica da realidade social, dedicados exclusivamente à oposição ou ao apoio sem limites aos governantes, desde a perspectiva estreita do individual.

03. Parecem ou são efetivamente incapazes de compreender que Estado e Governo não se confundem.

3. Os rábulas cram [ou são] mais humanos...

4. Papeles de filosofia, Editorial Biblos, Bucnos Aires, 1993, pp. $219 \mathrm{c}$ ss.

5. A cxpressão ć de Fábio Konder Comparato, Ensaios e pareceres de Direito Empresarial, Forcnse, Rio, 1978, p. 472.

6. Vide Eros Robcrto Grau c Luiz Gonzaga de Mcllo Belluzzo, A corrupção no Brasil, in Revista Brasilcira de Estudos Políticos, v. 80, 1995, p. 20 c meu O direito posto e o direito presstiposto, cit., p. 157.

7. Digesto, 50,16,15.

8. De Re Publica, J - 25, 39 . 
O Estado é uma instituição abstrata. Embora atue como um ator no embate das forças políticas, no exercício do poder estatal, o Estado é, concomitantemente, o troféu da política," disputado por essas forças, interessadas na conquista desse mesmo poder, o poder estatal.

Mas isso não são capazes de perceber. Ou, antes, sabem disso mas raciocinam, porque vítimas da doença crônica que os envelhece, como se não o soubessem. Uns combatem o "estatismo" porque estão a serviço, mesmo sem o saber, do poder empresarial; outros, simplesmente porque dirigem seus petardos contra o inimigo errado, não contra a tyrannia absque titulo ou a tyrannia quoad exercitium; não contra quem detém ou exerce o poder estatal de modo ilegítimo, mas contra a própria instituição estatal.

04. Falta aos nossos juristas o discernimento de que Estado e sociedade constituem dois momentos de uma só unidade e de que, como ensina Hegel, ${ }^{10} \mathrm{o}$ indivíduo obtém a sua liberdade substancial ligando-se ao Estado como à sua essência, como ao fim e ao produto da sua atividade.

Por isso - e a este ponto adiante retornarei - não há espaço para a liberdade individual senão no seio do Estado, senão enquanto os indivíduos permaneçam ligados ao Estado como à sua essência, como ao fim e ao produto da sua atividade individual.

05. Essa incompreensão ou ignorância deixa marcas profundas na doutrina, e de modo tal que, ainda que aqui se afirme a distinção entre interesse público primário e interesse público secundário, a coisa pública, aqui, é a coisa do Estado, não a coisa do povo.

Assim, porque ingênua" ou maliciosamente atuam como autêntica "linha auxiliar" dos que detém os poderes de fato hegemônicos, juristas que se recusam a praticar o pensamento crítico nutrem uma concepção do princípio da supremacia do interesse público que resulta por privilegiar não o que se poderia supor ser o interesse do Estado [= da sociedade], mas os interesses, privados, daqueles que detém o controle do Estado, usado o vocábulo "controle" aqui, sob o sentido de dominação.

Em seus tratados e cursos, bem assim em ensaios sibilinos, o Estado é descrito como deve ser, jamais como é.

06. A culpa porém não é exatamente deles, "sino de otros más duros y" siniestros"12 que desde a Colônia inseriram o individual em nosso Estado, de modo a

9. Vide Gcorges Burdeau, O Estado, trad. de Cascais Franco, Publicações Europa-Amćrica, Póvoa do Varzim, s/data, pp. 90 c ss.

10. Principes de la philosophie du droit, trad. par Robert Derathé, J. Vrin, Paris, 1993.

11. Vide Luciano de Oliveira e Affonso Cezar Pcrcira, Conflitos coletivos e acesso à Justiça, Fundaçào Joaquim Nabuco - Editora Massangana, Recifc, 1988, pp. 143 c 146-7.

12. Cf. o pocma de Mario Bencdetti, Hombre preso que mira su hijo, in Poemas de otros, cuarta cdición, Editorial Nucva lmagen, Bucnos Aires, 1989, p. 34. 
conformar e a determinar o interesse público, permitindo que relações promíscuas entre o público e o privado caracterizem os comportamentos de nossas elite ${ }^{13}$ de onde um modo de ser marcantemente cultural, enrustido tanto na classe média como nas de renda mais elevada.

Afinal de contas, é explicável que, por sermos assim, viceje, entre nós, e mesmo na doutrina produzida pelos juristas - porque o Direito, repita-se, é uma linguagem do social - confusão entre Estado e Governo e a equivocada concepção de que seria ele, o Estado, o grande vilão, o inimigo mais temivel da sociedade.

E isso de tal sorte se passa que chega mesmo a lembrar o Arrêt burlesque, composto por Boileau, ${ }^{14}$ que decreta o banimento da Razão da Universidade de Estagirita, além de proibir a um tal de Aristóteles de, na posse e no gozo da Razão, nela entrar, incomodá-la ou inquietá-la, sob pena de ser declarado jansenista e amigo de novidades...

07. Mas, além disso, especialmente no que tange ao Direito Administrativo, seus fundamentos estão ancorados, ainda, no pensamento liberal.

É bastante expresśiva a transcrição de um trecho da exposição de John Gilissen (Introdução histórica ao direito, trad. de A. M. Hespanha e L. M. Macaísta Malheiros, Fundação Calouste Gulbenkian, Lisboa, 1979, pp. 738-739): “Estas ideias tornar-se-ão, no século XVIII, num sistema geral de filosofia politica e social, sobretudo nos fisiocratas. A sociedade é considerada como um conjunto de homens livres e autônomos, não se ligam entre eles senão pela vontade. $O$ 'contrato social' de J. J. Rousseau repousa sobre autonomia absoluta da vontade dos individuos: 'Cada individuo obriga-se como quer, quando quer, mas apenas enquanto quer' Está aqui toda autonomia individual originária que a Revolução Francesa retomará e consagrará nas leis do seu periodo intermédio. Os juristas franceses do séc. XVIII, pela sua parte, estão atrasados em relação aos filósofos. Muitos práticos e comentadores, sobretudo do sul da França, continuam desesperadamente agarrados ao direito romano. No entanto, constata-se que são feitas tentativas que visam conciliar o formalismo romano da stipulatio e a autonomia da vontade. Domat escreve nas suas loix civiles dans leur ordre naturale (1689); 'qualquer convenção, tendo ou não nome, tem sempre seus efeitos e obriga ao que foi estipulado' O code civil de 1804 consagrará a autonomia da vontade sem desenvolver a sua teoria, e isto, nomeadamente, no art. 1134.": As convenções legalmente formadas impõe-se como lei àqueles que as celebraram Esta frase, mal redigida, pois nunca uma convenção pode ser assimilada a uma lei, vem do segundo projecto de Cambacères (dito o 'pequeno projecto'). No tribunado, Favard

13. Para uma visão de como, durante a Monarquia, a máquina pública cra manipulada pelos donos do poder como se fossem instalações do scu quintal privado, vide Antonio Cândido, Um fiuncionário da Monarquia, Editora Ouro Sobrc Azul, Rio de Janciro, 2002.

14. Oeuvres complètes de Boileau-Despréaux, nouvelle édition, Garnier Frères, Paris, 1861, pp. $191-193$ 
dirá : 'O contrato legalmente formado é uma emanação da lei e não menos sagrada do que ela: Esta teoria será plenamente desenvolvida no sec. XLX pelos grandes juristas da Escola exegética, respondendo, de resto, perfeitamente às concepções politicas $e$ económicas de então: o individualismo e o liberalismo. As fórmulas laissez faire, laissez passer e a lei da oferta e da procura repousam essencialmente sobre a liberdade contratual. $\dot{E}$ a idade de ouro da liberdade absoluta das convenções entre vendedores e compradores, entre patrões e operários, entre senhorios e inquilinos, etc. com a consequência da obrigação de as executar, mesmo se elas se revelassem injustas ou socialmente graves ou perigosas. Pois, então, estava-se convencido de que todo o compromisso livremente querido era justo"

Isso pode ser bem visualizado a partir da definição do objeto do Direito Administrativo, segundo um autor do Século XIX, Cabantous" : "Le droit administrative est l'ensemble de règles qui fixent les rapports des particuliers avec l'autorité administrative"

Essa visão do Direito Administrativo o concebe como um conjunto de disposições que tratam da ação da autoridade administrativa em relação aos particulares e "ne se propose que d'éclairer les particulieurs sur leurs droits et leurs obligations envers l'autorité" is

A razão de ser do Direito Administrativo encontra-se, nessa sua primeira versão, que inspira nossa doutrina até os dias que correm, unicamente na defesa do indivíduo em face do Estado. Em sua raiz, a fundamentar essa versão que é sem qualquer discussão assumida pela nossa doutrina, instala-se, como pressuposto dela, a crença em uma cisão entre Estado e sociedade.

08. Eis aí uma "verdade" dogmaticamente divulgada: Estado e sociedade estão situados em pólos opostos. E aqueles que essa "verdade" assumem nem ao menos se dão conta de que estão a conferir substância à receita segundo a qual o Estado deve manter-se a latere do mercado. ${ }^{17}$ De um lado o Estado; d'outro, o mercado, isto é, a sociedade. Tudo para deixar bem livre o poder empresarial, nadando de braçadas nos mercados.

Mal sabem, os que nisso acreditam, que o mercado é, no modo de produção capitalista, uma instituição jurídica, isto é, posta pelo Estado. E todos, todos eles, se encantam com a constituição de novos direitos como, por exemplo, os atribuídos aos consumidores e os relativos à proteção do meio-ambiente - sem se darem conta de que, embora isso efetivamente importe uma ampliação da esfera de direitos do homem, a sua conquista é admitida apenas na medida em que eles instrumentalizam a modernização e a legitimação capitalista.

15. Répétitions éctites surle Droit administratif, cinquième édition, Marescq Ainć, Paris, 1873, p. 2.

16. Cf. Cabantous, ob. cit., p. 3.

17. Notc-sc que, $\mathrm{cm}$ última instância, mercado c socicdade se confundem. 
09. Não é isto, contudo, o que ora desejo assinalar, senão que o Direito Administrativo constituído pela nossa doutrina, embalada pelo individualismo que, com marcas tão profundas, a caracteriza, é produto do liberalismo econômico gestado no século XIX, ainda que sob a máscara do liberalismo político.

Por isso mesmo essa doutrina, incapaz de compreender que a realidade não para quieta, planta suas bases sobre uma noção de legalidade ${ }^{18}$ estruturada sobre o dogma de uma "separação" dos poderes incompatível com a realidade, que execra a experiência de harmonia entre eles e a distribuição racional das funções normativa, administrativa e jurisdicional entre o Legislativo, o Executivo e o Judiciário. ${ }^{1 "}$ Nada mais conveniente, para que a função normativa regulamentar possa ser manipulada a serviço de determinados interesses e bem sabemos quais - do que ignorar os regulamentos erroneamente chamados de "delegados", sob o pretexto de que seriam, todos eles, inconstitucionais. O que se ignora não pode ser objeto de controle...

O serviço público é por ela concebido não como uma instituição cuja manutenção, pelo Estado, é indispensável à permanência da coesão social ${ }^{20}$, mas como um "regime jurídico" em estado puro, simetricamente bem proporcionado, fascinante assim como os jogos de vidrilhos que se olha contra o sol. Tudo pelas formas e em função das formas, sem que a essência do jurídico como elemento fundamental desse processo de adaptação social que o Direito é seja adequadamente considerado e ponderado.

Caminha devagar a nossa doutrina. Tome-se como exemplo a óbvia distinção entre os dois tipos ideais de empresas estatais, as prestadoras de serviço público, de uma banda; as que exploram atividade econômica, de outra. Apenas em 1973 alguém cogitou da distinção entre ambas, já na vigência do $§ 2^{\circ}$ do art. 170 da EC 1/69, quando Celso Antônio Bandeira de Mello (Prestação de serviços públicos e Administração Indireta, Editora Revista dos Tribunais, São Paulo, 1973, p. 101) observou que as segundas "configuram intervenções do Estado no domínio econômico" do que se extraiu a conclusão de que - como equivocadamente se admitiu que somente a União poderia intervir no domínio econômico - empresas estatais exploradoras de atividade econômica apenas poderiam existir no plano federal (conclusão da qual decorreria, v.g., no Estado de São Paulo, a inconstitucionalidade institucional do Banespa, da Vasp Aerofogrametria, da Cosesp, da Frutesp etc.). A distinção foi logo acompanhada por Hely Lopes Meirelles, em 1977, como anota Celso Antônio Bandeira de Mello (in RTDP 31/19). Cabe a Hely (Estudos e pareceres de Direito Público, v. II, Editora Revista dos Tribunais, São Paulo, 1977, p. 152), contudo, a virtude de ter, então, pela primeira vez mencionado que o $\S 2^{\circ}$ do art. 170 da EC $1 / 69$ diria respeito apenas às empresas estatais que explorassem atividade econômica; vale dizer,

18. Sobre a legalidade, vide meu $O$ direito posto e o direito presstuposto, cit., pp. 168-190.

19. Vide meu $O$ direito posto e o direito pressuposto, cit., pp. 225 c ss.

20. Vide meu $A$ orkem econômica na Constituição de 1988, 7a edição, Malhciros Editores, São Paulo, pp. 158 c ss. 
unicamente elas, não as prestadoras de serviços públicos, seriam regidas "pelas normas aplicáveis às empresas privadas, inclusive quanto ao direito do trabalho e ao das obrigações" Posteriormente, em 1.981, em meu Elementos de Direito Econômico (Editora Revista dos Tribunais, São Paulo, 1981, pp. 101 e ss., especialmente 105-6) detive-me sobre a questão, tormentosa porque mencionamos empresas estatais que exploram atividade econômica e empresas estatais que prestam serviço público e, não obstante, serviço público é atividade econômica! (vide, a esse respeito, meu $A$ ordem econômica na Constituição de 1988, cit., pp. 138 e ss.). Pois bem: embora tenha sido disseminado o entendimento de que o preceito veiculado pelo $\S 2^{\circ}$ do art. 170 da EC $1 /$ 69 - ao qual corresponde o $\S 1^{\circ}$ do art. 173 da Constituição de 1988 - aplica-se exclusivamente às empresas estatais que exploram atividade econômica em sentido estrito, ainda há quem hoje não o compreenda e, mais grave, sustente que a norma involucrada no art. 170, caput da Constituição vigente, limita o exercício, pelo Estado, da função de prestar serviços públicos...

A distinção entre juízos de legalidade e juízos de oportunidade, ainda que por ela reconhecida, enreda-a em descaminhos turbulentos, sempre por conta dos chamados "conceitos indeterminados", ${ }^{21}$ cuja determinação envolveria um juízo de oportunidade, não um juízo de legalidade. Daí a injustificável superposição entre discricionariedade e interpretação/aplicação do Direito. ${ }^{22}$

10. Assim se perde, essa doutrina, em um paradoxo insuperável, sem se dar conta de que, quando o Terceiro Estado percebeu que a legalidade dificultava a colocação da Administração a seu serviço, insitucionalizou duas válvulas de escape visando superar essa dificuldade, os regulamentos e discricionariedade. ${ }^{23}$

Combate os regulamentos, ${ }^{24}$ é verdade, mas ignorando-os e assim negando a necessidade, agora outra, de serem eles produzidos na esfera da capacidade normativa de conjuntura, ${ }^{25}$ âmbito da função normativa própria do Executivo. ${ }^{26}$ Contraditoriamente, contudo, acoca a teoria dos "conceitos indeterminados" dando franca liberdade ao exercício, pelo Executivo, da discricionariedade, que concebe como um poder da Administração, não como faculdade de formular juízos de oportunidade,

21. Sobre os conceitos juridicos c o conceito de noção, vide mcu Ensaio e discurso sobre a interpretação/aplicação do direito, Malheiros Editores, São Paulo, 2002, pp. 206 c ss., cspecialmente 211-215.

22. Vide mcu $O$ direito posto e o direito pressuposto, cit., pp. 210-214.

23. Idem, p. 181.

24. O fundamento da produção de regulamentos de exccução encontrar-sc-ia na tcoria dos "conccitos indeterminados", visto que prestar-sc-iam cles a regular situações $\mathrm{cm}$ que cabe discricionariedade administrativa no cumprimento da lei; vide meu $O$ direito posto e o direito pressuposto, cit., pp. 245-246.

25. Vide mcu $O$ direito posto e o direito pressuposto, cit., pp. 242.

26. O script ć porćm scguido à risca: como csses regulamentos são tidos como inconstitucionais, não sc os discutc, ficando clas por clas... 
exercitável exclusivamente nós estritos termos de lei, tal como por ela, lei, atribuída à autoridade administrativa. ${ }^{27}$

Daí porque se impõe a crítica e a defesa da legalidade, o que supõe, como premissa, o conhecimento da realidade, tal como ela é - e não tal como seria bom que ela fosse, segundo as crenças ideológicas de cada um e, nela, da necessária existência de regulamentos autorizados, que essa mesma doutrina chama de regulamentos "delegados"; regulamentos que são editados pelo Executivo em decorrência de atribuição explícita a ele, definida em lei, do exercício da sua função normativa regulamentar ${ }^{28}$ o que permite o controle da legalidade de todos eles.

Diante de argumentos irrefutáveis, os arautos da doutrina a eles escapam fazendo uso do velho método descrito por Galbraith (A economia e a arte da controvérsia, trad. de Gilberto Paim, Eidtora Fundo de Cultura, Rio de Janeiro, 1959, pp. 70-71): “É muitas vezes mais eficiente e invariavelmente poupa mais tempo e energia o ataque a uma posição como antiamericana, alienigena, extravagante, cheia de subterfúgios, inexequivel ou pró-comunista do que se se adotasse a técnica algo antiquada de examinar a questão em seus méritos" Limitam-se a afirmar que "todo marxista é autoritário e defende o Executivo forte" sem se dar conta de que é exatamente a tese dos "regulamentos delegados" que conduz ao descontrole da ação do Poder Executivo.

11. O fato é que essa doutrina se perde dentro de si própria porque construída desde a visão do individual, incapaz de perceber que urge reconstruirmos o Direito Administrativo como regulação da ação do Estado, voltada à satisfação do social e não apenas como conjunto de regras que regula as relações dos particulares com a autoridade administrativa.

Impõe-se substituirmos o Direito Administrativo/defesa do individuo por um outro, um Direito Administrativo/organização do Estado, que não apenas proteja o indivíduo, mas, ademais, esteja a serviço da satisfação do social. Um Direito Administrativo erguido sobre uma distinta noção de legalidade, que respeite aos procedimentos administrativos em si, e não atue exclusivamente na medida em que a eles seja correlata uma situação subjetiva do particular, sobre a qual tenha incidência um efeito de extinção ou limitação. Uma legalidade que não se manifeste exclusivamente no quadro da dialética da autoridade e da liberdade - uma necessariamente adversa da outra - mas que se imponha como regra de conteúdo [não apenas de limite] da atividade administrativa; legalidade que consubstancie a garantia de fins públicos, na implementação de políticas públicas, e não somente, e de modo exclusivo, a proteção do interesse privado ${ }^{29}$

A contribuição da literatura jurídica para uma noção de política puiblica

27. Vide meu $O$ direito posto'e o direito pressuposto, cit., pp. 222-223.

28. Idcm, pp. 249-254.

29. Vide meu $O$ direito posto e o direito pressuposto, cit. p. 174, c, mais amplamente, Massimo Scvero Giannini, Diritto Amministrativo, volume primo, Giuffrc̀, Milano, 1970, pp. 3-88. 
é bastante pequena. Um dos poucos juristas que escreveu sobre o tema, Fábio Comparato (Ensaio sobre o juizo de constitucionalidade de politicas públicas, in "Estudos em homenagem a Geraldo Ataliba 2 - Direito Administrativo e Direito Constitucional" Celso Antônio Bandeira de Mello (organizador), Malheiros Editores, São Paulo, 1997, pp. 343-359) salienta a novidade da política pública em relação às normas e aos atos, pois uma política pública não é uma coisa nem outra, ainda que as englobe como seus componentes. A política pública é uma atividade, vale dizer, um conjunto organizado de normas e atos tendentes à realização de um objetivo determinado. Esse conjunto a política - é unificado pela sua finalidade (veja-se, sobre elas, Maria Paula Dallari Bucci. Direito Administrativo e politicas públicas, tese, São Paulo, 2001). A verdade é que inúmeras vezes mencionamos a circunstância de o Direito deixar de meramente prestar-se à harmonização de conflitos e à legitimação do poder, passando a funcionar também como instrumento de implementação de politicas públicas, sem prestar a devida atenção às conseqüências disso. Em monografia sobre o tema, Charles-Albert Morand (Le droit néo-moderne des politiques publiques, L.G.D.J., Paris, 1999) analisa a profunda influência das práticas das políticas públicas sobre as formas jurídicas, afirmando mesmo a existência de um direito das políticas públicas, cujas características são a flexibilidade, o "flou" e a complexidade; por fim o autor indaga, para negá-lo, se esse direito das politicas públicas não estaria a dar lugar ao advento de um "direito pós-moderno" (ob. cit., pp. 194-211). O fato é que as reestruturações da "ordem capitalista" que assistimos durante a última década do século que passou não se limitam a encaminhar transformações isoladas na ordem juridica, identificadas na criação de um novo ramo ou mesmo de um novo instituto jurídico, mas apanham e afetam o Direito no seu todo. Em breve síntese podemos dizer que desde a sua segunda metade alterou-se, e de modo extremamente sensivel, o processo de juridificação do econômico e do social. E essa juridificação, que importou em uma cada vez mais apurada e refinada regulação de ambos, o econômico e o social - é verdade que negada nos últimos anos, os anos do neoliberalismo - essa juridificação, dizia, conduziu a enorme complexidade. Quem percorrer os índices das revistas jurídicas estrangeiras da década dos setenta, por exemplo, verificará que o fenômeno da "inflação normativa" desde então atormentava os estudiosos do Direito. Em 1970, André Hauriou mencionava o direito administrativo do aleatório; em 1983, Carbonier explorava a idéia de flexibilidade do direito. A todas essas transformações permaneceu como que imunizada nossa doutrina.

Um Direito Administrativo voltado à análise da funcionalidade da Administração, capaz de discernir, na complexidade da organização estatal, os inúmeros pontos a harmonizar na atuação das suas entidades não uma fotografia exatamente estática, mas o movimento de sua ação.

A múltipla e vária, quase verborrágica, produção de ensaios e teses sobre as "agências" (vide meu As agências, essas repartições públicas, in Regulação e Desenvolvimento, Calixto Salomão Filho [organizador], Malheiros Editores, São Paulo, 2002, pp. 25-28) é feita para e pelo lado de fora, sem que se detenham, os que escrevem sobre elas, no exame dos efeitos internos, no quadro da Administração ela própria, que 
decorrem da sua criação. Resultado é que mais não se faz, aqui, do que macaquear a doutrina norte-americana e da Comunidade Européia, sem nenhuma construção doutrinária atinente ao direito brasileiro (por exceção, entre uns poucos outros, Tercio Sampaio Ferraz Júnior, Agências reguladoras: legalidade e constitucionalidade, in Revista Tributária e de Finanças Públicas, n. 35, pp. 143 e ss., e Floriano Peixoto de Azevedo Marques, Regulação estatal e interesses públicos, Malheiros Editores, São Paulo, 2002).

interdisciplinar e reflexão. ${ }^{30}$

12. A reconstrução do Direito Administrativo demanda muita leitura

Seria conveniente, preliminarmente, tomassem conhecimento, os que aderirem a essa empreitada, de que o Estado é o espaço de socialização da liberdade.

Discorrendo sobre a relação entre Estado e sociedade, Hegel os toma como duas etapas de uma mesma ordem, a ordem política. A sociedade civil é um momento anterior ao Estado, uma etapa da ordem política; é um momento abstrato da pura e simples realidade da idéia moral objetiva; não é ainda a vontade substancial revelada "clara para si mesma, que se conhece e se pensa, e realiza o que sabe e porque sabe"; ela apenas se realiza como totalidade concreta no plano do Estado.

Leia-se, do Princípios da filosofia do direito, os $\$ \$ 182$ e $183 .{ }^{31}$

Após, o $§ 157, b),{ }^{32}$ de onde se extrai:

"A sociedade civil é associação cujos membros são individuos independentes, reunidos em uma universalidade formal em função das suas carências e pela constituição juridica (Rechtsverfassung) como instrumento de segurança da pessoa e da propriedade dos bens e por meio de uma regulamentação exterior destinada a satisfazer os interesses particulares e coletivos.

Este Estado exterior ${ }^{33}$ encontra sua unidade e sua coesão no fim e na realidade dessa universalidade substancial e da vida pública consagrada a essa universalidade, isto é, na constituição do Estado (Staatverfassung)."

E do $\S 257^{34}$ :

"O Estado é a realidade em ato da Idéia ética - o Espirito ético enquanto vontade substancial revelada, clara para si mesma, que se conhece e se pensa, e realiza o que sabe e porque sabe.

30. Cabe como u'a luva, aqui, a observação de Luciano de Olivcira c Affonso Cezar Pcreira [ob. cit., p. 148]: "não é possivel ao Direito Administrativo se pôr à margem de discussões que, na área das ciências sociais, enfocam a questâo do Estado a partir los dados da realidade atual e concreta"

31. Ob. cit., pp. 215-216.

32. Idcm, p. 198.

33. = regulamentação exterior.

34. Ob. cit., p. 258. 
O Estado tem a sua existência imediata no costume e a sua existência mediata na consciência de si, no saber e na atividade do individuo, que obtém a sua liberdade substancial nele [o Estado], que é sua essência,o fim e o produto da sua atividade."

Em seguida, do $\S 258^{35}$ se extrai:

"O Estado, enquanto realidade em ato de vontade substancial, realidade que ele, o Estado, adquire na consciência particular de si universalizada, ele [o Estado] é o racional em sí e para sí. Essa unidade substancial é fim em si, absoluto e imóvel, no qual a liberdade obtém o seu valor supremo, da mesma forma que este último fim possui um direito soberano perante os individuos cujo dever supremo está em serem membros do Estado.

(...)

Sendo, o Estado, Espírito objetivo, apenas como seu membro é que o individuo adquire verdade, uma existência objetiva e uma vida ética I = moralidade]. A associação como tal - associação dos indivíduos no Estado - é o verdadeiro conteúdo e o verdadeiro fim $^{36}$. porque o destino dos indivíduos está em participarem de uma vida coletiva; quaisquer outras satisfações, atividades e modalidades de comportamento encontram seu ponto de partida e seu resultado neste ato substancial e universal. Considerada abstratamente, a racionalidade consiste essencialmente na união íntima do universal e do particular. Considerada concretamente, como no caso se dá, ela consiste, quanto ao seu conteúdo, na unidade da liberdade objetiva [a vontade geral substancial] e da liberdade subjetiva como consciência individual e vontade que busca a realização de seus fins particulares."

Convém, por fim, a releitura de trecho do $\$ 260^{37}$ :

"Dai provem que o universal não tem valor e não pode ser realizado sem o interesse, a consciência e a vontade particulares e que, paralelamente, os individuos não vivem unicamente orientados pelo seu interesse, como simples pessoas privadas, sem relação com o universal [= com a vontade universal], sem exercer uma atividade consciente deste fim. O principio dos Estados modernos possui esta imensa força e profundidade: permitirem que o espirito da subjetividade alcance a extrema autonomia da particularidade pessoal ao mesmo tempo em que

35. Ob. cit., pp. 258-9.

36. Dos individuos.

37. Ob. cit, pág. 264. 
o reconduz à unidade substancial, assim mantendo esta unidade no seu próprio principio"

O Estado é a realidade em ato da liberdade concreta.

Ora, a liberdade concreta consiste em a individualidade pessoal, com os seus interesses particulares, possuir de tal modo o seu pleno desenvolvimento e o reconhecimento de seus direitos para si (nos sistemas da família e da sociedade civil) que, i. em parte, eles se integram por sí mesmos no interesse universal e ii. em parte, consciente e voluntariamente o reconhecem ${ }^{38}$ como seu particular espírito substancial e para ele agem como seu último fim.

A leitura de Hegel mostra bem que não há espaço para a liberdade individual senão no seio do Estado, senão enquanto os indivíduos permaneçam ligados ao Estado como à sua essência, como ao fim e ao produto da sua atividade individual. Ao compreendê-lo, extraímos todas as conseqüências da afirmação aristotélica de que o homem é, essencialmente, um animal político. "Evidentemente não sou parvo. Conheço bem quem arrebatou esse troféu, o Estado, e sei que o sistema capitalista da produção elege como ratio fundamentalis do ordenamento político o lucro e, no delírio neo-liberal, substitui a Happiness fundada na ética pela Happiness entendida como valor hedonistico" (cf. Alberto Donati, Giusnaturalismo e diritto europeo, Giuffrè, Milano, 2002, pp. 336 e 342).

13. Carecem de muita leitura e reflexão interdisciplinares os nossos dogmáticos, até para que fiquem cientes de que há sempre um grego ou um romano que já disse antes o que pensam ser uma criação intelectual sua. Lembro que mesmo Hegel bebeu nas fontes de Platão e de Aristóteles...

Isso, contudo, ainda é pouco, dado que, para que não lhes seja amoldável a última frase do antepenúltimo parágrafo do prefácio que von Ihering escreveu para a décima quarta edição do Der Kampf um's Recht" ["wunderliche Scherze, an denen man jenseits des Oceans sein Vergnügen findet"], é preciso também que se libertem da ilusão da certeza. O Direito, seguramente, não é um jogo de vidrilhos que se olha contra o sol...

Desafiá-los, isso me rejuvenesce, pois repito o que disse há alguns anos - não merece o privilégio de viver o seu tempo quem não é capaz de ousar... Ousar pelo social, jamais pelo individual de e em si mesmo.

São Paulo, novembro de 2002.

38. O interessc universal.

39. Manz'sche k. u. k. Hof-Verlags und Universitäts-Buchlandlung, Wien, 1900. 